\title{
Aurícula izquierda gigante. Caso clínico y revisión bibliográfica
}

\author{
Giant left atrial. Clinical case and bibliographic review
}

\author{
Eduardo D. Gabe' ${ }^{1}$ Diego Ascarrunz²
}

\section{RESUMEN}

Se presenta el caso clínico de un enfermo con insuficiencia valvular mitral no reumática portador de una aurícula izquierda gigante de $10,7 \mathrm{~cm}$ de diámetro anteroposterior, una de las mayores descriptas en la literatura. A propósito de este raro hallazgo se realizó una revisión de la literatura existente.

Palabras claves: fibrilación auricular, plicatura auricular, aurícula izquierda gigante, procedimiento de maze, enfermedad mitral no reumática.

\begin{abstract}
We present the unusual clinical case of a patient with non-rheumatic mitral valve insufficiency carrying a giant left atrium of $10.7 \mathrm{~cm}$ of anteroposterior diameter measured in a cardiac magnetic resonance, one of the largest atria described in the literature. With regard to this rare finding, a review of the existing literature was made
\end{abstract}

Keywords: atrial fibrillation, atrial plication, giant left atrium, maze procedure, non rheumatic mitral disease.

Revista Argentina de Cardioangiología Intervencionista 2018;9(1):47-48. Doi: 10.30567/RACI/201801/0047-0048

\section{INTRODUCCIÓN}

La aurícula izquierda (AI) gigante es en la actualidad un hallazgo poco habitual. Solía verse ocasionalmente en otra época en enfermos con valvulopatía mitral de origen reumático, y con mucha menor frecuencia en la insuficiencia mitral no reumática ${ }^{1}$. El ecocardiograma es el método complementario más simple para la determinación del tamaño, el área de la AI, el grado de regurgitación mitral y que puede reconocer la etiología de la enfermedad valvular. El desarrollo del conocimiento de las imágenes obtenidas con resonancia magnética nuclear (RMN) ha permitido realizar evaluaciones anatómicas y mediciones de gran precisión. El motivo de esta presentación fue mostrar las imágenes de RMN y radiológicas poco comunes de un enfermo portador de una AI gigante.

\section{CASO CLÍNICO}

Paciente de sexo masculino de 81 años con insuficiencia mitral no reumática, fibrilación auricular crónica conocida de varios años de evolución, en clase funcional II/ III por disnea, con astenia intensa, inestabilidad en su

\footnotetext{
. FACC. PhD. Cardiología ambulatoria. Sanatorio Otamendi y Miroli.

2. Residente Cardiología. Sanatorio Otamendi y Miroli.

$\triangle$ Correspondencia: Dr. Eduardo D Gabe. Arcos 2241. C1428AFI CABA. Rep. Argentina.edudagabe@gmail.com
}

Los autores no declaran conflictos de intereses.

Recibido: 28/02/2018|Aceptado:03/03/2018 marcha y trastornos neurológicos debidos a enfermedad de Parkinson. En la Figura 1, se observa la RMN (paneles A, B y C) y una radiografía de tórax (panel D) que testimonian una AI gigante por insuficiencia mitral no reumática, una de las de mayor dimensión descripta en la literatura (10,7 cm de diámetro anteroposterior).

\section{DISCUSIÓN}

La AI gigante es una afección rara, con una incidencia comunicada del 0,3\%, casi en su totalidad por causa de una valvulopatía mitral reumática. Aunque la enfermedad cardíaca reumática representa la causa principal de la AI gigante, se han informado otras etiologías ${ }^{1}$ y es consenso de la mayoría de los investigadores que ocurre con mucho menor frecuencia en la regurgitación mitral no reumática comunicándose casos en prolapso valvular mitral, miocardiopatía hipertrófica y amiloidosis ${ }^{2-4}$. La aurícula izquierda gigante tiene importantes efectos hemodinámicos y requiere un manejo específico. Clásicamente se aceptaba como definición de AI gigante a aquella que llega al lado lateral derecho de la pared del tórax en la radiografia simple en proyección anteroposterior ${ }^{5}$. Piccoli et al. ${ }^{6}$ definieron la AI gigante como una relación cardiotorácica mayor de 0,7 en combinación con un diámetro anteroposterior auricular izquierdo mayor de 8 $\mathrm{cm}$ en la ecocardiografía transtorácica. Otros investigadores $^{1,4}$ han considerado, para el diagnóstico AI gigante, el tamaño $\geq 6,5 \mathrm{~cm}$ en la vista paraesternal del eje largo ${ }^{1}$. Estos pacientes generalmente presentan fibrilación auri- 


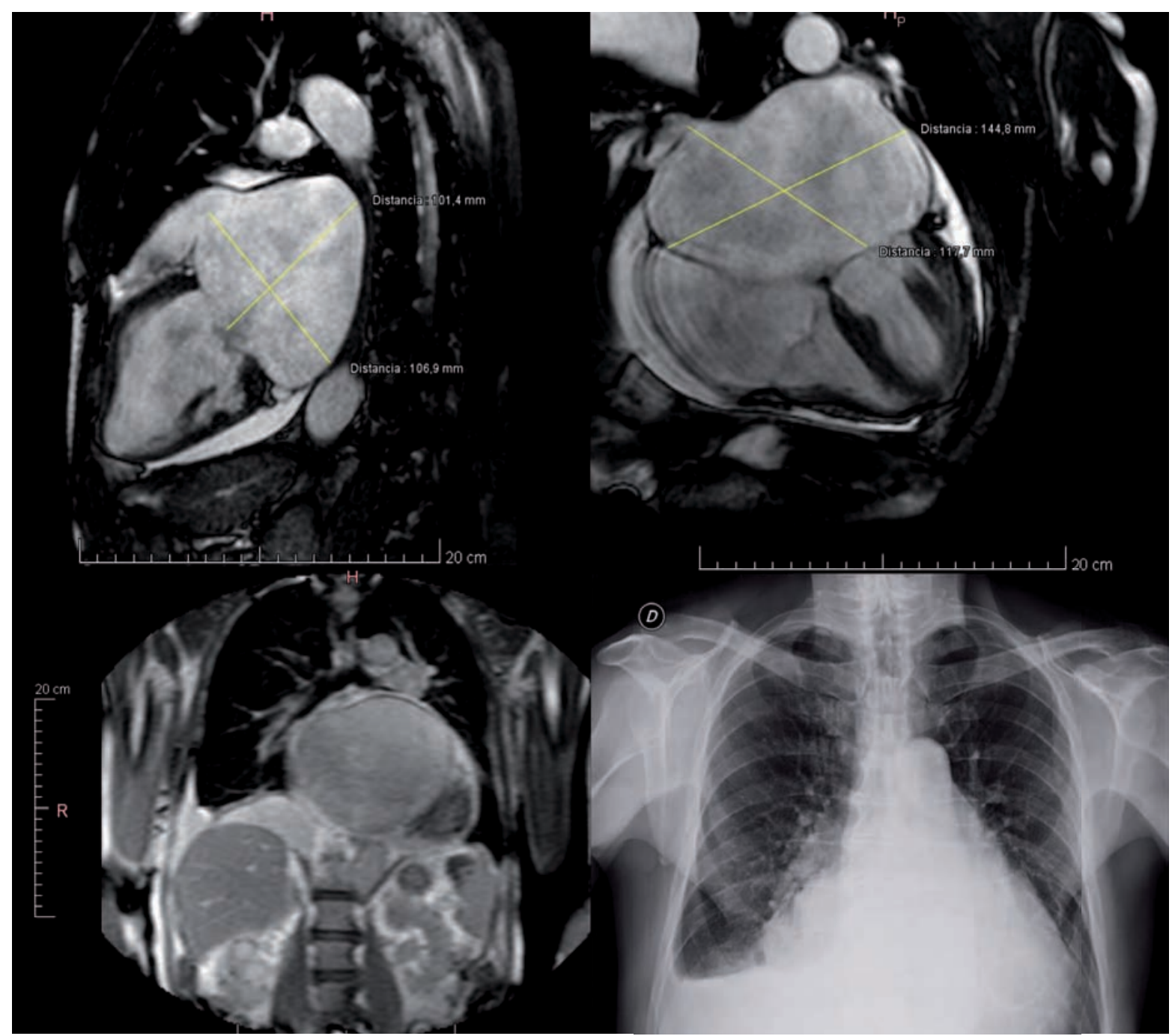

Figura 1. Resonancia magnética nuclear cardíaca donde se evidencia una aurícula izquierda gigante que ocupa gran parte de la cavidad torácica izquierda: (a): reconstrucción sagital; (b) reconstrucción axial; (c) reconstrucción coronal; (d) Radiografía anteroposterior de tórax

cular y con mucho menos frecuencia edema pulmonar debido a que una $\mathrm{AI}$ gigante atenúa el aumento rápido de la presión venosa pulmonar. El ecocardiograma, por su precisión en la valoración de las cavidades cardíacas, es la técnica diagnóstica de elección en estos pacientes. Sin embargo, se han descrito casos, en que el ecocardiograma puede ser insuficiente para definir con exactitud la anatomía de las aurículas y sus estructuras adyacentes, y se plantea la $\mathrm{RMN}^{7}$ como técnica complementaria para describir la forma, el tamaño y la presencia de trombos, especialmente en aquellos pacientes que requieren corrección quirúrgica.
En nuestro enfermo, en que el ecocardiograma fue insuficiente para definir con precisión las aurículas y sus estructuras adyacentes, se planteó la RMN como técnica complementaria, aunque luego desechó la opción quirúrgica. La cirugía de la mayoría de los casos implica el reemplazo o plástica de la válvula mitral junto con reducción del volumen de la AI. La indicación para la reducción de volumen AI es la presencia de compresión intracardíaca o extracardíaca por síntomas en órganos vecinos y la técnica quirúrgica más común es la resección parcial de la pared inferior y/o superior de la $\mathrm{AI}^{8}$.

\section{BIBLIOGRAFÍA}

1. El Maghraby A, Hajar R. Giant left atrium: A review. Heart Views. 2012;13:46-52. doi: 10.4103/1995-705X.99227

2. Brownsberger RJ, Morrelli HF. Hoarseness due to mitral valve prolapse. J Am Geriatr Soc. 1988;36:442-3.

3. Yuksel UC, Kursaklioglu H, Celik T. Apical hypertrophic cardiomyopathy with giant left atrium. Ara Bras Cardiol. 2007;88:e47.

4. Cheng Z, Fang Q, Liu Y. Cardiac amyloidisis with giant atria. Heart. 2010:96:1820.

5. Hurst JW. Memories of Patients With a Giant Left Atrium. Circulation. 2001:104:2630-2631.doi: 10.1161/hc4701.100775.

6. Piccoli GP, Massini C, Di Eusanio G, et al. Giant left atrium and mitral valve disease: Early and late results of surgical treatment in 40 cases. J Cardiovasc Surg. 1984;25:328-36.

7. Moral S, Fernández-Friera L, Sanz J. Aurícula izquierda gigante evaluada mediante resonancia magnética. Rev Esp Cardiol. 2011;64:232. DOI: 10.1016/j.recesp.2009.12.002.

8. Apostolakis E, Shuhaiber J. The surgical management of giant left atrium Eur J Cardiothorac Surg. 2008:33:182-90 